\title{
RT-qPCR for $P H O X 2 B$ mRNA is a highly specific and sensitive method to assess neuroblastoma minimal residual disease in testicular tissue
}

\author{
VICTORIA GRÈZE ${ }^{1,2}$, JUSTYNA KANOLD $^{1-3}$, FANNY CHAMBON ${ }^{1,2}$, PASCALE HALLE ${ }^{3}$, \\ ANNE-SOPHIE GREMEAU ${ }^{4}$, NATHALIE RIVES ${ }^{5,6}$, NADĖGE ROUEL ${ }^{2}$, \\ BRUNO PEREIRA $^{7}$, ANDREI TCHIRKOV $^{8,9}$ and FLORENCE BRUGNON ${ }^{4,9}$
}

\begin{abstract}
${ }^{1}$ Service Hématologie Oncologie Pédiatrique, CHU Clermont-Ferrand; ${ }^{2}$ Université Clermont Auvergne, INSERM-CIC 1405, Unité CRECHE; ${ }^{3}$ Centre de Biothérapie d'Auvergne; ${ }^{4}$ Assistance Médicale à la Procréation, CECOS, CHU Clermont-Ferrand, F-63000 Clermont-Ferrand; ${ }^{5}$ Normandie Univ, UNIROUEN, EA 4308 'Gamètogenèse et Qualité du Gamète'; ${ }^{6}$ Laboratoire de Biologie de la Reproduction-CECOS, Rouen University Hospital, F-76000 Rouen; ${ }^{7}$ Unité de Biostatistiques, Délégation

à la Recherche Clinique et l'Innovation; ${ }^{8}$ Cytogénétique Médicale; ${ }^{9}$ Université Clermont Auvergne, INSERM, U1240

Imagerie Moléculaire et Stratégies Théranostiques, CHU Clermont-Ferrand, F-63000 Clermont Ferrand, France
\end{abstract}

Received January 15, 2017; Accepted March 31, 2017

DOI: $10.3892 / 01.2017 .6238$

\begin{abstract}
Neuroblastoma (NB) is the most common type of extracranial solid tumor in children with a high prevalence in toddlers. For childhood cancer survivors, preservation of reproductive potential is an important factor for quality of life. The optimization of NB minimal residual disease (MRD) detection in testicular tissue is crucial to evaluate the risk of malignant cell reintroduction. The first step in the present study was to assess the accuracy of reverse transcription-quantitative polymerase chain reaction (RT-qPCR) to detect tyrosine hydroxylase $(T H)$, paired-like homeobox $2 \mathrm{~b}(\mathrm{PHOX} 2 \mathrm{~B})$ and doublecortin $(D C X)$ mRNA expression in frozen/thawed testicular tissues of patients with non-obstructive azoospermia (NOA) contaminated (in vitro model) with an increasing number of IMR-32 and SK-N-SH NB cells. Testicular tissues were frozen by slow or snap freezing. The second step was to determine the expression levels of these markers in testicular samples from 4 pre-pubertal males (2 with stage IV NB and 2 with non-NB malignancy). The yield of extracted RNA was similar in testicular samples frozen by slow or snap freezing. In the in vitro model, $T H$ and $D C X$ transcripts were detected in uncontaminated testicular tissues, whereas $P H O X 2 B$ mRNA
\end{abstract}

Correspondence to: Professor Florence Brugnon, Assistance Médicale à la Procréation, CECOS, CHU Clermont-Ferrand, 1 Place Lucie et Raymond Aubrac, F-63000 Clermont-Ferrand CEDEX 1, France

E-mail: fbrugnon@chu-clermontferrand.fr

Key words: neuroblastoma, minimal residual disease, reverse transcription quantitative polymerase chain reaction, testicular tissue, fertility preservation was not detected. There was a strong positive association between the number of NB cells used for contamination and PHOX2B transcript levels. For IMR-32 and SK-N-SH NB cell lines, specificity and sensitivity rates of detection were $100 \%$ for PHOX2B following in vitro contamination with 10 tumor cells. In testicular samples from pre-pubertal males with and without NB, PHOX2B mRNA expression was not observed, but high expression levels of $T H$ and $D C X$ mRNA were detected, which were similar to expression detected in the in vitro model. Among the markers used in blood and bone marrow for NB MRD studies, the detection of $P H O X 2 B$ transcripts by RT-qPCR may provide an accurate assessment of NB cells in testicular tissues from males who require fertility preservation.

\section{Introduction}

Neuroblastoma (NB) is the most common type of extracranial solid tumor in children, with a high prevalence in toddlers (1). At diagnosis, a high proportion of patients have stage IV metastatic disease (2). Intensive treatments for this type of cancer improved the long-term survival rate, including in children with high-risk NB (3). However, since dividing cells are the target of chemo- and radiotherapy, these treatments act not only on cancer cells but also on germ cells. Therefore, they may affect reproductive function, exposing patients to a high risk of infertility (4). Therefore, fertility preservation for boys with NB is currently recommended $(5,6)$. For childhood cancer survivors, preservation of reproductive potential is an important issue for quality of life (7).

When spermatogenesis is effective in pubertal males, sperm cryopreservation should be proposed (8). In pre-pubertal males, since spermatogenesis has not yet started, the preferred strategy is cryopreservation of testicular tissue (9-11). To date, no restoration of human fertility has been reported by the 
use of frozen/thawed testicular tissue. However, the animal data are promising, and births have been reported following spermatogonial stem cell transplantation or testicular tissue grafting in rodents or pigs (12-14). Furthermore, in vitro culture of testicular stem cells has been studied in mice for its potential to generate post-meiotic male gametes $(15,16)$. These preliminary results may offer the potential for fertility restoration in young males in the future. However, fertility restoration using cryopreserved testicular samples needs to be safe, without any risk of reintroducing cancer cells.

As a number of cases of metastatic testicular NB have previously been reported (17-19), the possible presence of malignant cells in cryopreserved testicular tissue involves a risk of recurrence of the primary disease following fertility restoration by germ cell transplantation. The detection of NB minimal residual disease (MRD) in blood and bone marrow of patients with metastatic NB was developed using reverse transcription-quantitative polymerase chain reaction (RT-qPCR) for tyrosine hydroxylase $(T H)$, paired-like homeobox $2 \mathrm{~b}$ (PHOX2B) and doublecortin (DCX) transcripts (20-22). These transcripts represent useful and clinically significant biomarkers of MRD in the blood and bone marrow of metastatic NB cells. However, these biomarkers have not been assessed for NB MRD detection in testicular tissue. The optimization of NB MRD detection in testicular tissue is crucial to evaluate the risk of malignant cell reintroduction. This detection method needs to be applicable for testicular samples frozen by slow freezing and for testicular tissues immediately following surgical collection, which could subsequently be frozen by snap freezing until RNA extraction is performed. This would allow detection of MRD for previously cryopreserved testicular tissues and for future testicular sample collections.

Therefore, the first objective of the present study was to assess the accuracy of NB MRD detection. This was performed by quantification of $T H, D C X$ and $P H O X 2 B$ transcripts in human testicular tissues, cryopreserved by slow or snap freezing and contaminated in vitro with increasing number of tumor cells from two NB cell lines. Once accuracy was assessed in this in vitro model, the expression levels of these three biomarkers were evaluated in frozen testicular samples from pre-pubertal males with and without NB.

\section{Materials and methods}

Experimental design. The specificity and sensitivity of NB MRD detection were assessed by RT-qPCR quantification of $T H, P H O X 2 B$ and $D C X$ mRNA expression in thawed testicular tissues that were contaminated with IMR-32 and SK-N-SH human NB cell lines (CCL-127 and HTB-11; American Type Culture Collection, Manassas, VA, USA). Prior to these experiments, IMR-32 and SK-N-SH cells were investigated for positivity and stability of $T H, P H O X 2 B$ and $D C X$ mRNA expression in the subclones.

Subsequently, thawed testicular tissue from patients with non-obstructive azoospermia (NOA) were contaminated with 0 (negative control), 10, 100 and 1,000 IMR-32 and SK-N-SH tumor cells from human NB cell lines. The contamination procedure was performed at room temperature and took $20 \mathrm{~min}$. RNA extraction was performed immediately following contamination, without any additional incubation of the samples. Experiments involving contamination with 10 and 100 cells were performed in duplicate for each sample (Fig. 1). Once contamination was achieved, RNA extraction and RT-qPCR were performed. Testicular tissues frozen either by snap or slow freezing methods were used to investigate whether the freezing method may interfere with RT-qPCR analysis.

Following assessment of MRD detection accuracy in the in vitro model, thawed testicular samples obtained from pre-pubertal males with stage IV NB and with non-NB malignancy (Ewing tumor) were analyzed in order to expand the method to include pre-pubertal testicular tissues.

Patients and samples. Testicular tissues were obtained from 20 males (mean age, 32.4 years; range, 25-38 years) with NOA between November 2014 and September 2015 at the University Hospital of Clermont-Ferrand (Clermont-Ferrand, France). The patients underwent testicular sperm extraction for intra-cytoplasmic sperm injection. Following sperm retrieval and freezing, the remaining testicular tissue sample would usually be destroyed, but in this instance it was used for the present study.

In addition, testicular tissues obtained from 2 pre-pubertal patients with stage IV NB in January 2012 (patient A, aged 3 years) and in April 2014 (patient B, aged 2 years) and 2 pre-pubertal patients with Ewing sarcoma in January 2016 (patients C and D, aged 6 years) were analyzed. Sample A was obtained at the University Hospital of Rouen (Rouen, France). Samples B, C and D were obtained at the University Hospital of Clermont-Ferrand (Clermont-Ferrand, France). Bilateral testis samples from patients A, B and C were evaluated. For patient $\mathrm{D}$, only one sample of the right testis was available and evaluated. The median weight of the testicular samples for these 4 patients was $12 \mathrm{mg}$.

The present study was approved by the Committee for Personal Protection (DC 2008 558). Written informed consent was obtained from all patients prior to enrollment in the present study and for inclusion of the testicular samples in the GERMETHEQUE biobank (NFS 96900, www.chu-toulouse. $\mathrm{fr} /$ germetheque-centre-de-ressources-biologiques). In the case of two males with NB who succumbed to disease prior to the study, informed and written consent was obtained from their parents. The study was declared on the clinicaltrial.gov website (no. NCT02400970).

Freezing and thawing. For the testicular tissues obtained from adult patients with NOA, the samples were first cut into 6 thin fragments of equal size $\left(\sim 1 \mathrm{~mm}^{3}\right)$ following weighing. Subsequently, the testicular fragments (equally sized samples) were frozen by using the slow ( $\mathrm{n}=10$ patients) or snap ( $\mathrm{n}=10$ patients) freezing method. The testicular tissues obtained from pre-pubertal males had been previously frozen by slow freezing for the two males with NB and by snap freezing for the males with Ewing sarcoma.

The slow freezing method was performed as previously described and validated by Rives et al (10). For the snap freezing method, testicular samples were put in cryogenic vials and immediately frozen by immersion in liquid nitrogen. For both freezing procedures, the samples were stored in cryogenic vials (CRYO BIO SYSTEM, L'Aigle, France). The 


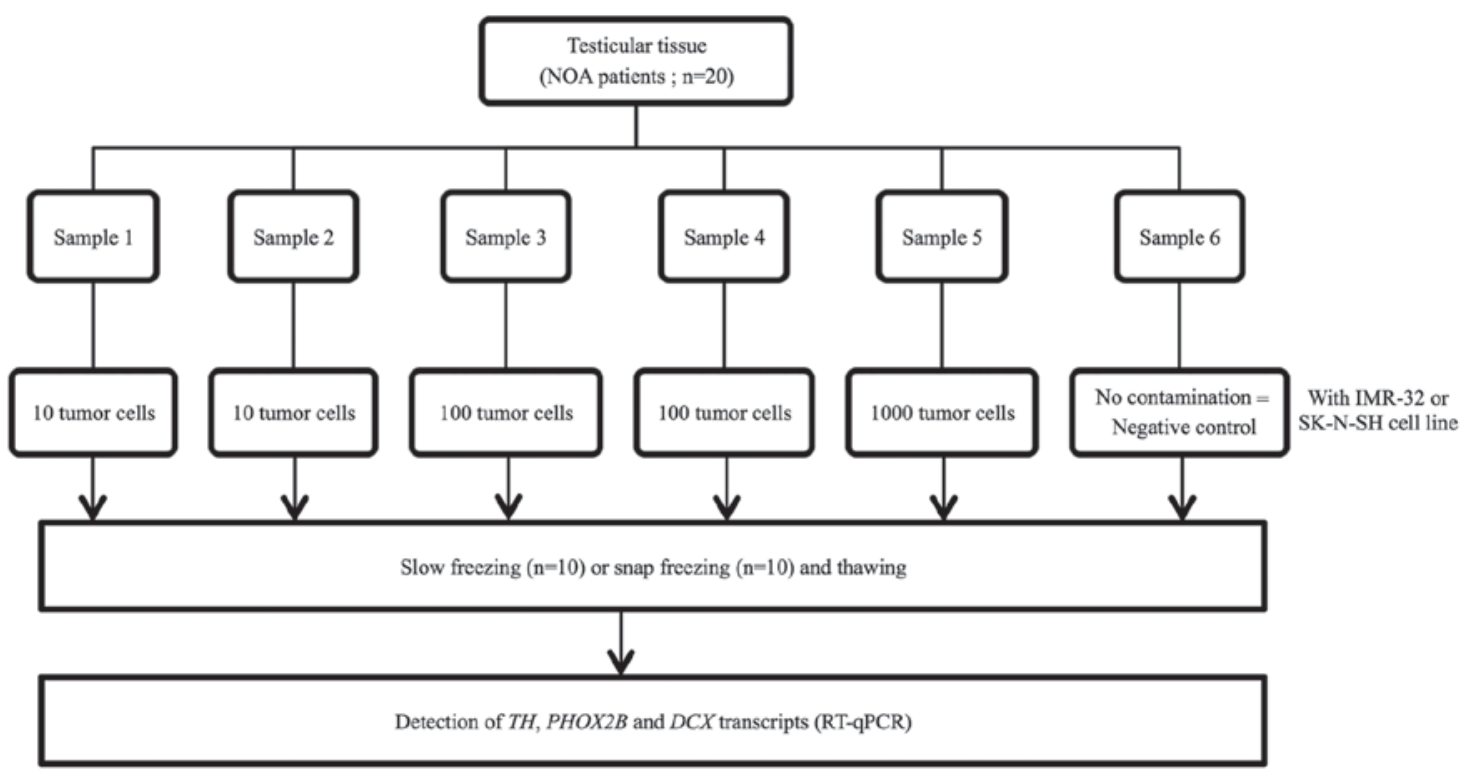

Figure 1. Experimental design for detection of $T H, P H O X 2 B$ and $D C X$ transcripts in thawed testicular tissues following NB cell contamination by IMR-32 and SK-N-SH cell lines. Each testicular sample from patients with NOA was sectioned into 6 thin samples of equal size $\left(\sim 1 \mathrm{~mm}^{3}\right)$. Each testicular sample was contaminated with an increasing number of IMR-32 and SK-N-SH NB cells prior to slow or snap freezing and detection of TH, Phox 2B and DCX transcripts by RT-qPCR. NOA, non-obstructive azoospermia; NB, neuroblastoma; TH, tyrosine hydroxylase; PHOX2B, paired-like homeobox 2b; DCX, doublecortin; RT-qPCR, reverse transcription-quantitative polymerase chain reaction.

same thawing procedure was used for testicular tissues frozen by slow or snap freezing. The cryogenic vials were thawed at $37^{\circ} \mathrm{C}$ for $3 \mathrm{~min}$ and placed into three baths of Leibovitz's L-15 medium (Eurobio, Courtaboeuf, France) for $5 \mathrm{~min}$ for each step at room temperature.

Culture of IMR-32 and SK-N-SH subclones. IMR-32 and SK-N-SH are well-established subclones of human cell NB. The IMR-32 cell line was maintained in Dulbecco's modified Eagle's medium (PAN-Biotech, Aidenbach, Germany), supplemented with $10 \%$ fetal calf serum (PAN-Biotech), $4 \mathrm{mmol} / \mathrm{l}$ L-glutamine, $10 \mathrm{UI} / \mathrm{ml}$ penicillin and $10 \mu \mathrm{g} / \mathrm{ml}$ streptomycin (PAN-Biotech) (23). The SK-N-SH cell line was maintained in Iscove's modified Dulbecco's Medium (PAN-Biotech), supplemented with $10 \%$ fetal calf serum, $4 \mathrm{mmol} / 1 \mathrm{~L}$-glutamine, $10 \mathrm{UI} / \mathrm{ml}$ penicillin and $10 \mu \mathrm{g} / \mathrm{ml}$ streptomycin. Cell counting analysis was performed twice prior to each contamination using the Malassez cell counting chamber. Blue trypan staining (diluted 1/20 with phosphate buffered saline) for $10 \mathrm{~min}$ at room temperature was used to assess cell viability. For IMR-32 and SK-N-SH cell lines, the viability was always $\geq 85 \%$. The cell counting analysis and cell viability test were performed with a light microscope by an experienced observer prior to each contamination test.

Detection of TH, DCX and PHOX2B mRNA expression by $R T-q P C R$. RNA was extracted using TRIzol ${ }^{\circledR}$ reagent (Invitrogen; Thermo Fisher Scientific, Inc., Waltham, MA, USA), according to the manufacturer's instructions. RNA was treated with DNAse I (Roche Diagnostics, Meylan, France) to remove any contaminating DNA. A total of $1 \mu \mathrm{g}$ RNA was reverse-transcribed using SuperScript II (Invitrogen; Thermo Fisher Scientific, Inc.). The target $T H, D C X$ and $P H O X 2 B$ gene transcripts and the reference $\beta$-2-microglobulin $(\beta 2 M)$ housekeeping gene transcript were measured using the LightCycler 480 RT-PCR system (Roche Diagnostics), using previously reported primers and probes (24). The sequences are provided in supplementary methods of the publication (24). The cycling conditions were as follows: $10 \mathrm{~min}$ at $95^{\circ} \mathrm{C}$, followed by 40 cycles of $95^{\circ} \mathrm{C}$ for $15 \mathrm{sec}$ and $60^{\circ} \mathrm{C}$ for $1 \mathrm{~min}$. Absolute quantification analysis with the LightCycler software was performed to determine transcripts numbers, as described previously (20). Briefly, standard curves were generated using serial dilutions of plasmid containing a known number of molecules of each transcript and used to calculate the number of transcripts in the samples. The number of the reference $\beta 2 M$ gene transcripts was used for the normalization of data. Normalized data were expressed as the copy numbers of target transcripts per $10^{6}$ copies of $\beta 2 M$ transcripts. The PCR reactions were performed in triplicate.

Statistical analysis. Statistical analysis was performed using Stata software (version 13; StataCorp LP, College Station, TX, US). The results for quantitative parameters were presented as the mean \pm standard deviation, according to statistical distribution (assumption of normality assessed by Shapiro-Wilk's test). The investigation of associations between quantitative parameters was based on the estimation of correlation coefficients (Pearson's or Spearman's rho according to statistical distribution, noted r). Subsequently, in order to take into account differences between and within subject variability (due to several measurements for a given patient), random-effects for correlated measures were performed instead of the usual statistical tests, which would not be appropriate as the hypothesis of independence of data was not possible. The assumption of normality of residuals was studied using the Shapiro-Wilk test. When appropriate (data not exhibiting normal distributions), a logarithmic transformation was performed in order to achieve normality assumption 
and to ensure the correct use of previous analyses. Finally, receiver operating characteristic curve analysis was performed to evaluate sensitivity and specificity of RT-qPCR to detect the expression of $T H, P H O X 2 B$ and $D C X$ mRNAs in testicular tissue. All tests described in this section are two-sided, with a type I error set at $\alpha=0.05$ : $\mathrm{P}<0.05$ was considered to indicate a statistically significant difference.

\section{Results}

Yield of RNA extraction from testicular tissue frozen using snap and slow freezing methods. The median weight of testicular samples from 20 men with NOA was 96 mg (33-210 mg). Each testicular sample was sectioned into six equal size samples with a median weight of $14 \mathrm{mg}(6-46 \mathrm{mg})$. The median RNA yield from these samples was $15 \mu \mathrm{g}(0.6-36.6 \mu \mathrm{g})$. The amount of RNA obtained per mg of tissue did not differ between the testicular samples frozen by snap $(0.87 \mu \mathrm{g} / \mathrm{mg})$ or slow freezing $(0.80 \mu \mathrm{g} / \mathrm{mg})$ methods $(\mathrm{P}>0.05)$.

Expression of TH, PHOX $2 B$ and DCX transcripts in IMR-32 and $S K-N-S H$ cell lines. The expression levels of $T H, P H O X 2 B$ and $D C X$ transcripts in IMR-32 and SK-N-SH cell lines were evaluated for each artificial tumor contamination experiment (Fig. 2). Overall, the cell lines exhibited high levels of expression of the three markers, with the mean normalized values of $3.3 \times 10^{5}$ for $T H, 1.9 \times 10^{7}$ for $P H O X 2 B$ and $3.1 \times 10^{7}$ for $D C X$ in IMR-32 cells and $3.0 \times 10^{5}$ for $T H, 9.5 \times 10^{6}$ for $P H O X 2 B$ and $3.6 \times 10^{7}$ for $D C X$ in SK-N-SH cells. The levels of transcripts indicated minimal variations between different experiments, which were $<1.3$ fold. The average fold changes in transcript levels in IMR-32 and SK-N-SH cells were 1.26 and 1.22 for $T H, 1.26$ and 1.25 for PHOX2B and 1.28 and 1.27 for $D C X$, respectively. These data indicated the high reproducibility of the cell line models in terms of marker mRNA expression.

Detection of TH, PHOX2B and DCX transcripts in frozen testicular samples contaminated with IMR-32 and SK-N-SH $N B$ cells. In the present study, expression of $T H$ transcripts was observed in negative control testicular samples $(n=10)$. Expression of $T H$ transcripts was detected in samples frozen by snap freezing (IMR-32, 537 copy number $/ 10^{6} \beta 2 M$ copy number; SK-N-SH, 475 copy number $/ 10^{6} \beta 2 M$ copy number) and by slow freezing (IMR-32, 363 copy number $/ 10^{6} \beta 2 M$ copy number; SK-N-SH, 490 copy number $/ 10^{6} \beta 2 M$ copy number; Fig. 3A). Compared with the negative control (uncontaminated testicular samples), the level of $T H$ mRNA was significantly higher in testicular samples contaminated with 100 and 1,000 NB cells from IMR-32 and SK-N-SH cell lines, respectively $(\mathrm{P}<0.001)$. There was no significant difference between the levels of $T H$ mRNA detected in testicular samples contaminated with $10 \mathrm{NB}$ cells and uncontaminated samples (IMR-32, $\mathrm{P}=0.18$; SK-N-SH, $\mathrm{P}=0.24)$. For determination of $T H$ expression, the specificity and sensitivity rates were $100 \%$ when 100 NB cells were used for contamination.

$P H O X 2 B$ mRNA was not detected in the uncontaminated testicular samples (Fig. 3B) frozen either by the snap or slow freezing method $(\mathrm{n}=10)$. $P H O X 2 B$ transcripts were detected at significantly different levels following contamination of testicular samples with 10, 100 and 1,000 NB cells $(\mathrm{P}<0.001$
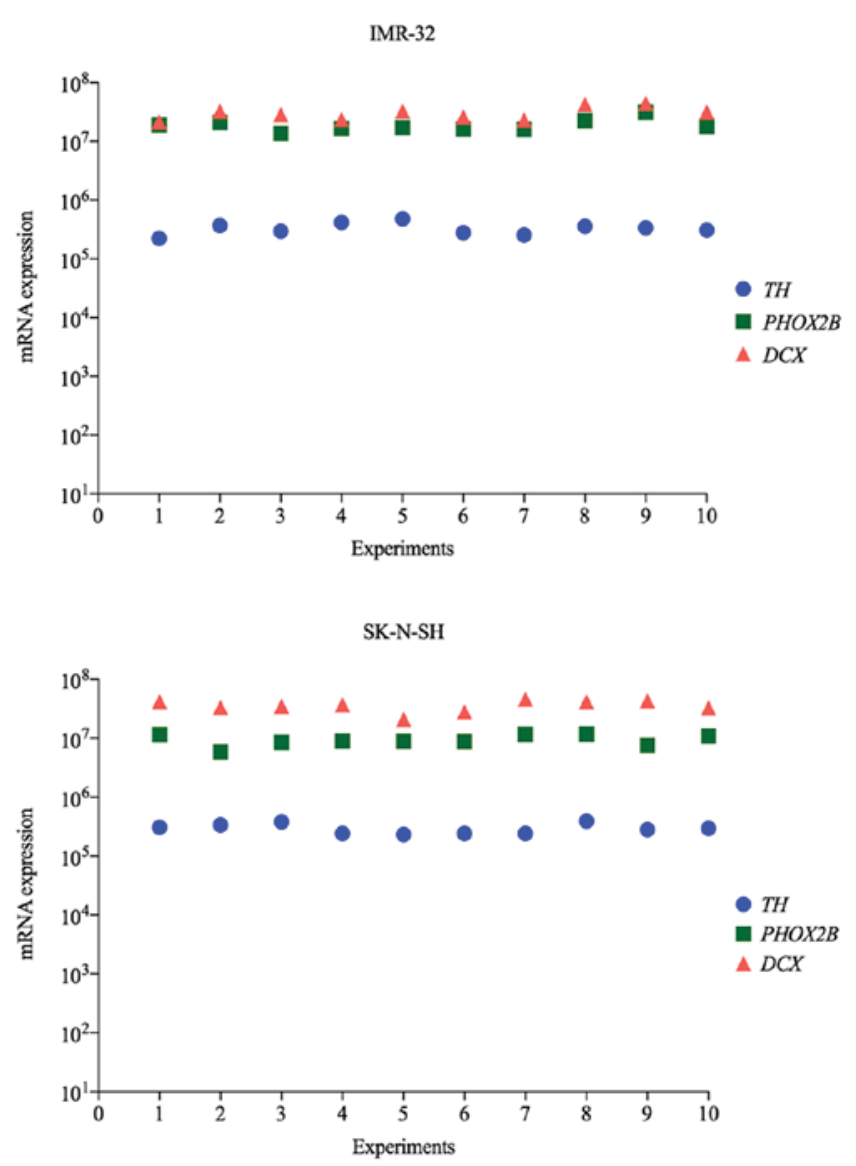

Figure 2. Normalized expression of $T H, P H O X 2 B$ and $D C X$ in IMR-32 and SK-N-SH cell lines (per $10^{6} \beta 2 M$ transcripts). For each cell line, 10 different subcultures were used for tumor contamination experiments. These subcultures exhibited minimal variations in the levels of the three mRNAs $(<1.3$ fold), indicating a good reproducibility of contamination experiments. $\mathrm{TH}$, tyrosine hydroxylase; PHOX2B, paired-like homeobox 2b; DCX, doublecortin; $\beta 2 \mathrm{M}, \beta-2$-microglobulin.

for IMR-32 and SK-N-SH). Furthermore, there was a strong linear correlation between the number of NB cells used for contamination (10, 100 and 1,000 NB cells) and the levels of PHOX2B mRNA (r=0.96 for IMR-32 and SK-N-SH). The specificity and sensitivity rates for $P H O X 2 B$ mRNA detection were $100 \%$ following contamination by 10 NB IMR-32 or SK-N-SH cells.

High expression levels of $D C X$ mRNA were detected in negative controls $(n=10)$ frozen by snap freezing (IMR-32, 73,231 copy number $/ 10^{6} \beta 2 M$ copy number; SK-N-SH, 68,386 copy number $/ 10^{6} \beta 2 M$ copy number) and by slow freezing (IMR-32, 64,811 copy number $10^{6} \beta 2 M$ copy number; SK-N-SH, 78,810 copy number $/ 10^{6} \beta 2 M$ copy number) methods (Fig. 3C). Furthermore, there was no significant difference in $D C X$ mRNA levels between the negative controls and samples contaminated with 10, 100 and 1,000 NB cells.

Analysis of TH, DCX and PHOX2B mRNA expression levels in testicular tissues of pre-pubertal males. In the testicular samples obtained from two pre-pubertal NB stage IV males, the levels of $T H$ mRNA were similar in the right (patient A, 431 copy number $/ 10^{6} \beta 2 M$ copy number; patient B, 469 copy number $/ 10^{6} \beta 2 M$ copy number) and left (patient A, 420 copy 

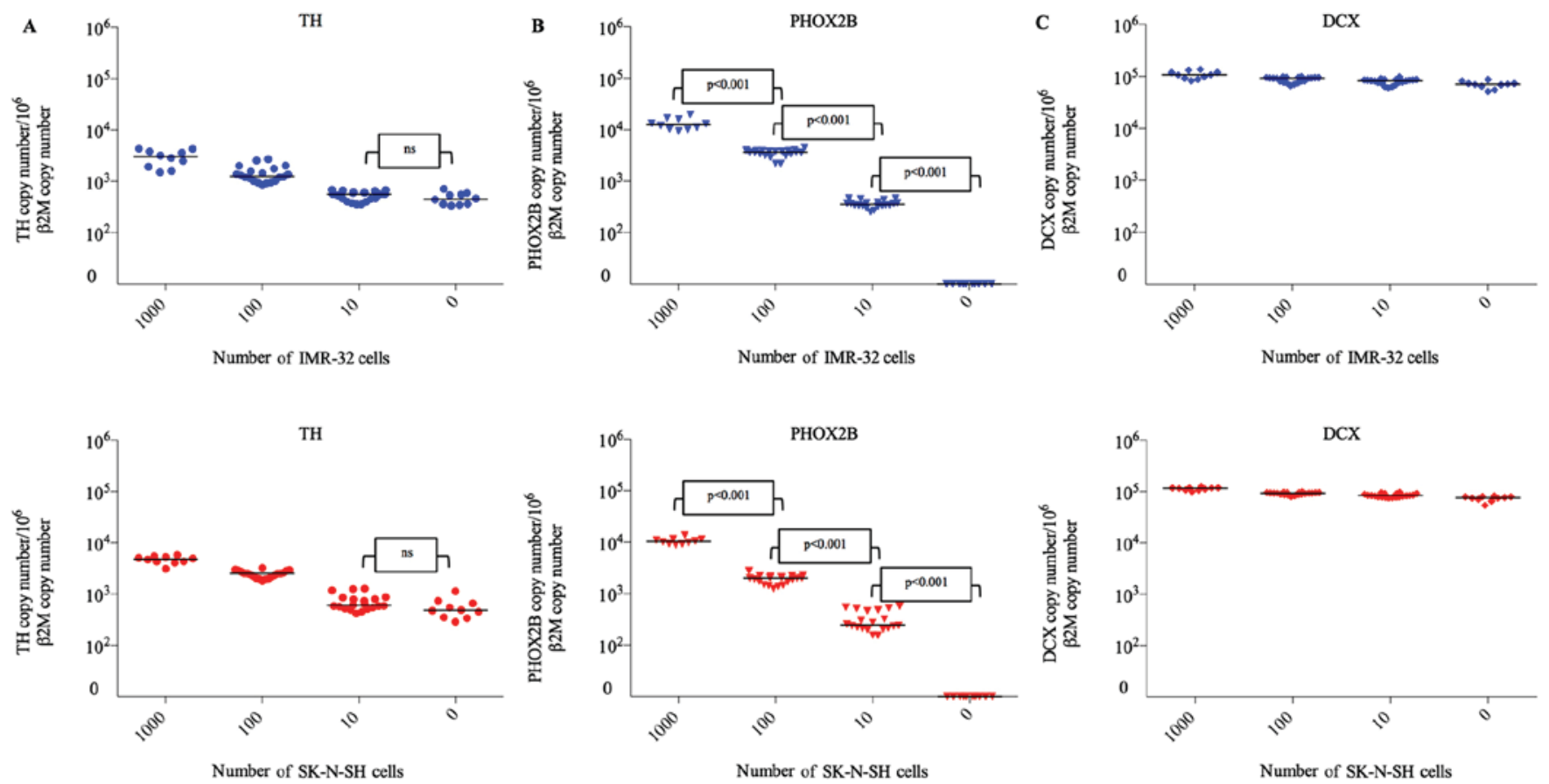

Figure 3. Relative expression of (A) $T H$, (B) PHOX2B and (C) DCX in thawed testicular tissues following contamination by neuroblastoma cell lines (0, 10, 100 and 1,000 cells). Each symbol represents one testicular tissue fragment. Blue, IMR-32 cells; red, SK-N-SH cells. ns, no significant; TH, tyrosine hydroxylase; PHOX2B, paired-like homeobox 2b; DCX, doublecortin.

number $/ 10^{6} \beta 2 M$; patient $\mathrm{B}, 371$ copy number $/ 10^{6} \beta 2 M$ copy number) testis tissue samples. PHOX2B mRNA was undetectable in the testis samples of patient A and B. Similar high levels of $D C X$ mRNA were observed in the right (patient A, 58,700 copy number $/ 10^{6} \beta 2 M$; patient B: 48,297 copy number $/ 10^{6} \beta 2 M$ ) and left (patient A: 51,280 copy number $/ 10^{6}$ $\beta 2 M$; patient B: 44,738 copy number $/ 10^{6} \beta 2 M$ ) testis samples.

In the samples obtained from two pre-pubertal males with no-NB malignancy (Ewing sarcoma; patients $\mathrm{C}$ and D), mRNA $T H$ levels were similar in the right (patient $C, 684$ copy number $/ 10^{6} \beta 2 M$; patient $\mathrm{D}, 500$ copy number $/ 10^{6} \beta 2 M$ ) and left (patient $C, 736$ copy number $/ 10^{6} \beta 2 M$ copy number) testis. $P H O X 2 B$ mRNA was not detected in testis samples obtained from either male. High levels of $D C X$ mRNA were observed in the right (patient $\mathrm{C}, 53,690$ copy number $/ 10^{6} \beta 2 M$; patient $\mathrm{D}$, 59,380 copy number $/ 10^{6} \beta 2 M$ copy number) and left (patient C, 59,380 copy number $/ 10^{6} \beta 2 M$ copy number) testis samples.

High expression levels of $T H$ and $D C X$ observed in the testicular tissues of the four pre-pubertal males were similar to the high expression levels detected in uncontaminated testicular samples (negative controls) in the in vitro model described previously in the results section.

\section{Discussion}

Given the increased survival rate of patients with NB and the cytotoxic effects of therapies used for treatment of this cancer (25), fertility preservation is highly recommended for these children. Therefore, for a pre-pubertal male facing sterilizing chemotherapy, testicular biopsy may be performed as a preventive strategy. Freezing testicular tissue allows subsequent transplantation either by infusion of a testicular cell suspension into the seminiferous tubules (26) or intra-testicular grafting of tissue (27). However, $>60 \%$ of children with metastatic NB have circulating tumor cells at the time of diagnosis (28). Although testis is not the most frequent NB invasion site, numerous cases of testicular NB metastasis have been described previously. Simon et al (19) reported testicular metastasis in 10/1,076 male patients with NB using the data of the Cooperative German Neuroblastoma trials. Kushner et al (29) demonstrated 11 positive cases in a series of 289 male NB autopsies. Nistal et al (30) also reported two cases of testicular metastases confirmed by histological examination in a total of $216 \mathrm{NB}$ patients. Therefore, the possible presence of NB cells in testicular tissue collected from NB males should be taken into account to avoid reintroducing cancer cells when the thawed testicular sample is used to restore fertility. However, in all of the previous studies mentioned, only histological analyses were performed. As the sensitivity of MRD detection by histological analysis is lower compared with RT-qPCR, the actual frequency of NB infiltration in testis may be higher.

In the present study, sufficient amounts of RNA were extracted from small testicular samples to perform RT-qPCR in optimal conditions and to analyze the level of three transcripts associated with NB. The use of a small quantity of testicular tissue to detect NB MRD ensures that a sufficient amount of sample remains for fertility preservation in pre-pubertal males, in whom large surgical retrieval is not always possible due to age and small testis size. The present study did not observe any effect of the freezing method on the yield of RNA extracted. Therefore, the RT-qPCR method may be performed on testis samples that have already been cryopreserved using slow freezing and on samples, which are cryopreserved by snap freezing at the time of surgical retrieval for subsequent analysis. 
In the present study, an in vitro model of NB dissemination in human testicular tissue was established to evaluate the sensitivity and specificity for the detection of NB mRNAs. The SK-N-SH and IMR-32 tumor cell lines used for contaminations are well known and were established from human NB. SK-N-SH cells were established from the bone marrow metastasis from a 4 year-old Caucasian child (31). IMR-32 cells were obtained from a metastatic site in an abdominal mass in a 13 month-old Caucasian male with NB. The tumor was diagnosed as NB with rare areas of organoid differentiation (32). Therefore, SK-N-SH and IMR-32 human cell lines are highly representative of metastatic NB. In the present study, $T H, D C X$ and $P H O X 2 B$ mRNAs were expressed at high levels in SK-N-SH and IMR-32 cell lines. The testicular samples that were used to validate the in vitro contamination model were obtained from adult males with NOA, as it was unethical to perform these preclinical tests with healthy pre-pubertal testicular samples. Similar to pre-pubertal patients, testicular biopsies from patients with NOA contain low numbers or absence of mature germ cells.

In children with NB, metastatic tumor cells were previously detected in the bone marrow and peripheral blood by RT-qPCR for NB-specific target genes, including $T H, D C X$ and $P H O X 2 B(24,33,34)$. To the best of our knowledge, this is the first study to quantify the expression level of these transcripts in human testicular tissues to detect MRD. $T H$ encodes for the key enzyme involved in the synthesis of catecholamines, which serves a functional role in the testis. A previous study provided evidence that Leydig cells exhibited close similarity to cathecholaminergic nerve cells with high expression of TH (35). This may be explained by a developmental arrest of Leydig cells at the immature state (36). In addition, Leydig cells are characterized as non-dividing cells with characteristics of early stem cell-like progenitors with endocrine, neuronal and glial cell features (37). Although $\mathrm{TH}$ is one of the most commonly used targets for MRD detection in peripheral blood and bone marrow of patients with NB $(20,21)$, the use of this transcript as an MRD marker in testicular samples is hindered by its background expression detected in uncontaminated samples of patients with NOA and pre-pubertal males with and without NB. Therefore, it is hypothesized that the background expression of $\mathrm{TH}$ may be due to the presence of Leydig cells $(35,37)$. Furthermore, $100 \%$ sensitivity and specificity rates of $T H$ detection were only observed when $100 \mathrm{NB}$ cells were used for contamination, which may suggest that the accuracy of this marker for NB MRD detection is insufficient for detection in human testicular samples.

Previously, the expression level of other transcripts, including $D C X$ and $P H O X 2 B$, were demonstrated to be useful for NB MRD detection in bone marrow and peripheral blood from patients with metastasis (24). DCX is involved in the signaling pathway that regulates microtubule in migrating neurons (38). A previous study reported a high expression of a $D C X$ homolog, $D C D 1$, in human testis (39). This may explain the lack of sensitivity and specificity that was observed for analysis of $D C X$ expression in the in vitro model in the present study, and the high expression of $D C X$ in pre-pubertal males with or without NB. $P H O X 2 B$ encodes a transcription factor involved in the development of the autonomous nervous system $(34,40)$. It was previously revealed that $P H O X 2 B$ is a highly specific marker for sensitive MRD detection of NB in the bone marrow, peripheral blood and harvested hematopoietic stem cells (40). To the best of our knowledge, the present study demonstrated for the first time a high sensitivity and specificity of RT-qPCR analysis for $P H O X 2 B \mathrm{mRNA}$, enabling the detection of as few as $10 \mathrm{NB}$ cells in a testis sample. The absence of background $P H O X 2 B$ expression in uncontaminated testicular samples underlines the high specificity of this marker. Furthermore, $\mathrm{PHOX} 2 \mathrm{~B}$ expression was not detected in testicular samples of pre-pubertal males without $\mathrm{NB}$ in the present study. The present study demonstrated that NB MRD assessment in human testicular tissue by the detection of PHOX2B by RT-qPCR is highly accurate. It is unknown whether MRD marker genes of NB are up- or downregulated during treatment $(23,24)$, so a panel of PCR targets may be required to overcome tumor heterogeneity (41). Since $T H$ and $D C X$ transcripts are not sensitive and specific NB markers in testicular tissues, it will be necessary to continue the evaluation of other known NB-specific transcripts. Analysis of NB mRNA is able to detect the presence of malignant cells but cannot predict their vitality or invasive potential. Therefore, further studies are required to investigate the risk of tumor dissemination on MRD-positive pre-pubertal testicular samples by xenotransplantation in rete testis of nude or severe combined immunodeficiency (SCID) mice.

In conclusion, the present study provides evidence that among the established NB markers for MRD analysis of blood and bone marrow using RT-qPCR, $P H O X 2 B$ mRNA may provide an accurate assessment of MRD in testicular tissues for males that require fertility preservation. These preliminary results require confirmation by a further study of testicular tissues from a large cohort of pre-pubertal males with NB and additional studies are warranted to evaluate the safety threshold by xenotransplantation in nude or SCID mice.

\section{Acknowledgments}

The present authors would like to thank the Ligue contre le Cancer for supporting the project. The authors also thank Mrs. Camille Meindre and Mrs. Lucie Vivier (Centre de Biothérapie d'Auvergne, CHU Clermont-Ferrand, Clermont-Ferrand, France), Mrs. Sandra Carlet-Dollet and Mr. Cyril Bouche (Assistance Médicale à la Procréation, CECOS, CHU Clermont-Ferrand, Clermont-Ferrand, France), Mrs. Marine Nervi and Mrs. Farida Godeau (Cytogénétique Médicale, CHU Clermont-Ferrand, Clermont-Ferrand, France) and Mrs. Alexandra Usclade (Unité CRECHE, INSERM-CIC 1405, Université Clermont Auvergne, Clermont-Ferrand, France) for their excellent technical assistance.

\section{References}

1. Kaatsch P: Epidemiology of childhood cancer. Cancer Treat Rev 36: 277-285, 2010.

2. Haase GM, Perez C and Atkinson JB: Current aspects of biology, risk assessment, and treatment of neuroblastoma. Semin Surg Oncol 16: 91-104, 1999.

3. Oberthuer A, Hero B, Berthold F, Juraeva D, Faldum A, Kahlert Y, Asgharzadeh S, Seeger R, Scaruffi P, Tonini GP, et al: Prognostic impact of gene expression-based classification for neuroblastoma. J Clin Oncol 28: 3506-3515, 2010.

4. Brougham MF and Wallace WH: Subfertility in children and young people treated for solid and haematological malignancies. Br J Haematol 131: 143-155, 2005. 
5. Lee SJ, Schover LR, Partridge AH, Patrizio P, Wallace WH, Hagerty K, Beck LN, Brennan LV and Oktay K; American Society of Clinical Oncology: American Society of Clinical Oncology recommendations on fertility preservation in cancer patients. J Clin Oncol 24: 2917-2931, 2006.

6. Loren AW, Mangu PB, Beck LN, Brennan L, Magdalinski AJ, Partridge AH, Quinn G, Wallace WH and Oktay K; American Society of Clinical Oncology: Fertility preservation for patients with cancer: American Society of Clinical Oncology clinical practice guideline update. J Clin Oncol 31: 2500-2510, 2013.

7. Sudour-Bonnange $\mathrm{H}$, Tabone MD, Thomas-Teinturier C, Pacquement H, Oberlin O, Marec-Berard P, Laurence V, Aubier F, Duranteau L, Bernier-Chastagner V, et al: Fertility preservation in children and teenagers with cancer. Bull Cancer 100: 727-735, 2013 (In French).

8. Daudin M, Rives N, Walschaerts M, Drouineaud V, Szerman E, Koscinski I, Eustache F, Saïas-Magnan J, Papaxanthos-Roche A, Cabry-Goubet R, et al: Sperm cryopreservation in adolescents and young adults with cancer: Results of the French national sperm banking network (CECOS). Fertil Steril 103: 478-486.e1, 2015.

9. Wyns C, Curaba M, Vanabelle B, Van Langendonckt A and Donnez J: Options for fertility preservation in prepubertal boys. Hum Reprod Update 16: 312-328, 2010.

10. Rives N, Milazzo JP, Travers A, Arkoun B, Bironneau A, Sibert L, Liard-Zmuda A, Marie-Cardine A, Schneider P, Vannier JP and Macé B: Cryopreservation of testicular tissue in children. Bul Acad Natl Med 197: 877-886, 2013 (In French).

11. Goossens E, Van Saen D and Tournaye H: Spermatogonial stem cell preservation and transplantation: From research to clinic. Hum Reprod 28: 897-907, 2013.

12. Shinohara T, Inoue K, Ogonuki N, Kanatsu-Shinohara M, Miki H, Nakata K, Kurome M, Nagashima H, Toyokuni S, Kogishi K, et al: Birth of offspring following transplantation of cryopreserved immature testicular pieces and in-vitro microinsemination. Hum Reprod 17: 3039-3045, 2002.

13. Kanatsu-Shinohara M, Ogonuki N, Inoue K, Ogura A, Toyokuni S and Shinohara T: Restoration of fertility in infertile mice by transplantation of cryopreserved male germline stem cells. Hum Reprod 18: 2660-2667, 2003.

14. Nakai M, Kaneko H, Somfai T, Maedomari N, Ozawa M, Noguchi J, Ito J, Kashiwazaki N and Kikuchi K: Production of viable piglets for the first time using sperm derived from ectopic testicular xenografts. Reproduction 139: 331-335, 2010.

15. Stukenborg JB, Schlatt S, Simoni M, Yeung CH, Elhija MA, Luetjens CM, Huleihel $M$ and Wistuba J: New horizons for in vitro spermatogenesis? An update on novel three-dimensional culture systems as tools for meiotic and post-meiotic differentiation of testicular germ cells. Mol Hum Reprod 15: 521-529, 2009

16. Reuter K, Ehmcke J, Stukenborg JB, Simoni M, Damm OS, Redmann K, Schlatt S and Wistuba J: Reassembly of somatic cells and testicular organogenesis in vitro. Tissue Cell 46: 86-96, 2014.

17. Kumari PK, Surendran N, Chellam VG, Pillai GR and Ramachandran K: Neuroblastoma with testicular metastasis. Review of literature and report of a case. Indian J Cancer 31: 52-55, 1994.

18. Casola G, Scheible W, Leopold GR: Neuroblastoma metastatic to the testis: ultrasonographic screening as an aid to clinical staging. Radiology 151:475-476, 1984.

19. Simon T, Hero B and Berthold F: Testicular and paratesticular involvement by metastatic neuroblastoma. Cancer 88: 2636-2641, 2000.

20. Tchirkov A, Paillard C, Halle P, Bernard F, Bordigoni P, Vago P, Deméocq F and Kanold J: Significance of molecular quantification of minimal residual disease in metastatic neuroblastoma. J Hematother Stem Cell Res 12: 435-442, 2003.

21. Burchill SA, Lewis IJ, Abrams KR, Riley R, Imeson J, Pearson AD, Pinkerton R and Selby P: Circulating neuroblastoma cells detected by reverse transcriptase polymerase chain reaction for tyrosine hydroxylase mRNA are an independent poor prognostic indicator in stage 4 neuroblastoma in children over 1 year. J Clin Oncol 19: 1795-1801, 2001.

22. Chambon F, Tchirkov A, Pereira B, Rochette E, Deméocq F and Kanold J: Molecular assessment of minimal residual disease in PBSC harvests provides prognostic information in neuroblastoma. Pediatr Blood Cancer 60: E109-E112, 2013.
23. Stutterheim J, Zappeij-Kannegieter L, Ora I, van Sluis PG, Bras J, den Ouden E, Versteeg R, Caron HN, van der Schoot CE and Tytgat GA: Stability of PCR targets for monitoring minimal residual disease in neuroblastoma. J Mol Diagn 14: 168-175, 2012.

24. Viprey VF, Gregory WM, Corrias MV, Tchirkov A, Swerts K, Vicha A, Dallorso S, Brock P, Luksch R, Valteau-Couanet D, et al: Neuroblastoma mRNAs predict outcome in children with stage 4 neuroblastoma: A European HR-NBL1/SIOPEN study. J Clin Oncol 32: 1074-1083, 2014

25. Pinto NR, Applebaum MA, Volchenboum SL, Matthay KK, London WB, Ambros PF, Nakagawara A, Berthold F, Schleiermacher G, Park JR, et al: Advances in risk classification and treatment strategies for neuroblastoma. J Clin Oncol 33: 3008-3017, 2015.

26. Brünsten RL and Zimmermann JW: Spermatogenesis following male germ-cell transplantation. Proc Natl Acad Sci USA 91: 11298-11302, 1994.

27. Baert Y, Van Saen D, Haentjens P, In't Veld P, Tournaye H and Goossens E: What is the best cryopreservation protocol for human testicular tissue banking? Hum Reprod 28: 1816-1826, 2013.

28. Yáñez Y, Hervás D, Grau E, Oltra S, Pérez G, Palanca S, Bermúdez M, Márquez C, Cañete A and Castel V: TH and DCX mRNAs in peripheral blood and bone marrow predict outcome in metastatic neuroblastoma patients. J Cancer Res Clin Oncol 142: 573-580, 2016.

29. Kushner BH, Vogel R, Hajdu SI and Helson L: Metastatic neuroblastoma and testicular involvement. Cancer 56: 1730-1732, 1985.

30. Nistal M, González-Peramato P and Paniagua R: Secondary testicular tumors. Eur Urol 16: 185-188, 1989.

31. Gilbert LC and Wachsman JT: Characterization and partial purification of the plasminogen activator from human neuroblastoma cell line, SK-N-SH. A comparison with human urokinase. Biochim Biophys Acta 704: 450-460, 1982.

32. Tumilowicz JJ, Nichols WW, Cholon JJ and Greene AE: Definition of a continuous human cell line derived from neuroblastoma. Cancer Res 30: 2110-2118, 1970.

33. Viprey VF, Corrias MV, Kagedal B, Oltra S, Swerts K, Vicha A, Ladenstein R and Burchill SA: Standardisation of operating procedures for the detection of minimal disease by QRT-PCR in children with neuroblastoma: Quality assurance on behalf of SIOPEN-R-NET. Eur J Cancer 43: 341-350, 2007.

34. Viprey VF, Lastowska MA, Corrias MV, Swerts K, Jackson MS and Burchill SA: Minimal disease monitoring by QRT-PCR: Guidelines for identification and systematic validation of molecular markers prior to evaluation in prospective clinical trials. J Pathol 216: 245-252, 2008

35. Davidoff MS, Ungefroren H, Middendorff R, Koeva $Y$, Bakalska M, Atanassova N, Holstein AF, Jezek D, Pusch W and Müller D: Catecholamine-synthesizing enzymes in the adult and prenatal human testis. Histochem Cell Biol 124: 313-323, 2005.

36. Seil FJ, Johnson ML, Nishi R and Nilaver G: Tyrosine hydroxylase expression in non-catecholaminergic cells in cerebellar cultures. Brain Res 569: 164-168, 1992.

37. Schulze W, Davidoff MS and Holstein AF: Are Leydig cells of neural origin? Substance P-like immunoreactivity in human testicular tissue. Acta Endocrinol (Copenh) 115: 373-377, 1987.

38. Oltra S, Martinez F, Orellana C, Grau E, Fernandez JM, Cañete A and Castel V: The doublecortin gene, a new molecular marker to detect minimal residual disease in neuroblastoma. Diagn Mol Pathol 14: 53-57, 2005.

39. Zeng L, Gu S, Li Y, Zhao E, Xu J, Ye X, Wu Q, Wang L, Xie Y and Mao Y: Identification of a novel human doublecortin-domain-containing gene (DCDC1) expressed mainly in testis. J Hum Genet 48: 393-396, 2003.

40. Stutterheim J, Gerritsen A, Zappeij-Kannegieter L, Kleijn I, Dee R, Hooft L, van Noesel MM, Bierings M, Berthold F, Versteeg R, et al: PHOX2B is a novel and specific marker for minimal residual disease testing in neuroblastoma. J Clin Oncol 26: 5443-5449, 2008.

41. Corrias MV, Haupt R, Carlini B, Cappelli E, Giardino S, Tripodi G, Tonini GP, Garaventa A, Pistoia V and Pistorio A: Multiple target molecular monitoring of bone marrow and peripheral blood samples from patients with localized neuroblastoma and healthy donors. Pediatr Blood Cancer 58: 43-49, 2012. 